\title{
Possibility of simulating natural circulation in fast neutron reactors using a light water test facility ${ }^{*}$
}

\author{
Viktor I. Slobodchuk ${ }^{1}$, Dmitry A. Uralov ${ }^{1}$, Ekaterina A. Avramova ${ }^{1}$ \\ 1 Obninsk Institute for Nuclear Power Engineering NRNU MEPhI, 1 Studgorodok, 249040 Obninsk, Kaluga Reg., Russia \\ Corresponding author: Viktor I. Slobodchuk (slobovic@mail.ru)
}

Academic editor: Georgy Tikhomirov • Received 26 June 2021 Accepted 21 October 2021 • Published 17 Dedcember 2021

Citation: Slobodchuk VI, Uralov DA, Avramova EA (2021) Possibility of simulating natural circulation in fast neutron reactors using a light water test facility. Nuclear Energy and Technology 7(4): 349-355. https://doi.org/10.3897/nucet.7.78625

\begin{abstract}
The paper evaluates the possibility of modeling the heat transfer phenomena in a liquid-metal coolant using a light water test facility. It considers the natural circulation of the coolant in the upper plenum of the fast-neutron reactor. The sodium-cooled BN-1200 reactor was selected as the reactor installation to be modeled. The development of novel reactor designs must be based on the results of experimental studies. Some problems of modeling thermohydraulic processes in BN type reactors are studied by using sodium test facilities. Experimental studies of natural convection processes using light water test facilities can be considered as a good alternative to those using sodium test facilities. To validate the model, the similarity theory and the "black box" method were used and their principles and applicability were analyzed. Using the "black box" method makes it possible to avoid detailed modeling of such components as the reactor core and heat exchangers, replacing them by a simplified representation of these components to simulate the integral characteristics of the existing real life equipment. The paper considers the basic criteria which determine the similarity of the thermohydraulic processes under study. The governing criteria of similarity were estimated based on the fundamental differential equations of natural convection heat transfer. Based on these criteria, a set of dimensionless values was obtained which show the correlation between the model parameters and the characteristics of the reactor facility. Besides, generalized relationships were derived which can be used to estimate the scaling factors for calculating the key values of the reactor facility based on the model parameters. These relationships depend on the thermal-physics parameters of the working fluids, the geometrical scale value and the ratio of the thermal power of the model to that of the reactor facility, i.e., model-to-reactor thermal power ratio. The conditions under which it is possible to model sodium coolant by light water with adequate accuracy were analyzed. An example is given of the numerical values of the scaling factors for one of the reference light water test facilities. The paper uses the experience of a number of foreign researchers in this field, in particular, the accepted assumptions which do not result in serious loss in modeling accuracy. According to the available estimates, the assumptions used do not result in considerable losses in accuracy. Thus, the natural circulation of the sodium coolant in the upper plenum of the fast-neutron reactor can be simulated with adequate accuracy by using light water test facilities.
\end{abstract}

\section{Keywords}

Fast neutron reactors, natural circulation, thermohydraulic simulation, similarity theory

* Russian text published: Izvestiya vuzov. Yadernaya Energetika (ISSN 0204-3327), 2021, n. 3, pp. 146-157. 


\section{Introduction}

Currently, much attention is given to designs of reactor facilities using liquid metal coolants and fast neutron reactors. This is due to the fact that the use of power units with such reactor facilities holds great promise not only for electricity generation but also for nuclear fuel breeding, as well as for spent fuel reprocessing, which will make it possible to achieve a closed NPP fuel cycle in the future. Achieving such a cycle is critical to improving the sustainability of nuclear power and switching to generation IV nuclear reactors in many countries including Russia.

The reactor technologies with the closed fuel cycle should be thoroughly explored and tested in accordance with the accepted conservative approach. The scientific and experimental framework for the designs under consideration can be provided, specifically, by the results of experiments to simulate the thermohydraulic performance of reactor facilities.

Some fast neutron reactor designs, e.g. BN-1200, consider sodium as the coolant since it offers the best possible neutronic and thermohydraulic performance, compatibility with various structural materials, relative ease of being kept clean in the process of operation, and relatively low cost. Sodium, however, is highly chemically active and generates a huge amount of energy on contact with water. In addition, experimental facilities designed to investigate its performance need to be equipped with extra heating and sodium purification systems with cold traps. It is necessary to use electromagnetic pumps, which make flowcharts more complex and expensive. Therefore, though the use of sodium in commercial plants is widespread, it is not cost-effective to use in research facilities.

This study aims to find out if it is possible to simulate, with the use of water, the thermohydraulic processes in the liquid metal coolant flowing in the reactor upper plenum under natural circulation conditions. In the 1990s, Japanese researchers suggested that, given certain assumptions, it was possible to simulate the thermohydraulic performance of liquid sodium using water test facilities. The idea was supported in a number of studies (Ishii and Kataoka 1982, Ishii and Kataoka 1984, Eguchi and Takeda 1993, Ieda et al. 1993, Takeda and Koga 1993, Eguchi et al. 1997). The use of water-based facilities makes it possible to get a more detailed insight into the physics of the processes taking place in the sodium circuit. The results of such studies will allow simplifying the experimental simulation process, e.g., for the fast reactor cooldown processes.

This type of research is based on two key approaches: the "black box" method and the similarity theory (Bomelburg 1968, Ishii and Kataoka 1982, Ishii and Kataoka 1984, Eguchi and Takeda 1993, Ieda et al. 1993, Takeda and Koga 1993, Ushakov and Sorokin 1993, Eguchi et al. 1997, Ushakov and Sorokin 1999). The need for using the similarity theory is dictated by a large number of arguments, on which the sought-after quantities depend in traditional numerical and experimental methods. By com- bining physical quantities into dimensionless groups, this method allows reducing greatly the number of arguments to facilitate calculations.

The most important prerequisites for using the similarity theory are geometric and temporal similarities of the model and the real system. A reactor facility with the $\mathrm{BN}-1200$ reactor was used as the reference facility in this study. This is due to the relevance of the reactor design concerned for the Russian nuclear power (Ashirmetov and Yershov, Mitenkov). BN-1200 is one of the facilities using sodium coolant. The V-200 (SARKh) experimental test facility is considered as a 1:10 model for the selected reactor facility. Its flow diagram reflects the arrangement of coolant circulation in the primary circuit of the $\mathrm{BN}$ reactor in rated and cooldown modes. The equipment layout in the test facility is the same as that in the real reactor. A schematic representation of the test facility developed by the authors based on the SARKh documentation is shown in Fig. 1.

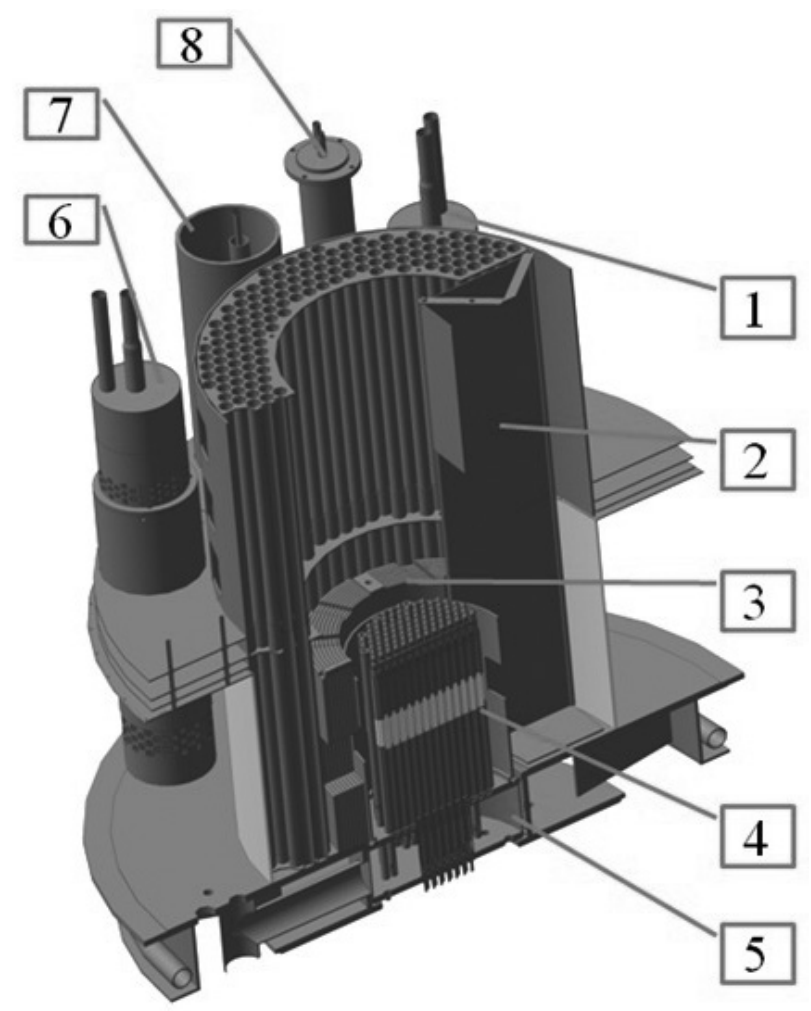

Figure 1. Design of the SARKh test facility with a cut along the elevator baffle: 1, 6 - intermediate heat exchangers (IHX); 2 - elevator baffle; 3 - in-tank protection components; 4 - core with FA dummies; 5 - reactor pressure chamber; 6 - reactor coolant pump (RCP) mockup; 8 emergency heat exchanger (EHX).

Since it is not possible to produce a detailed miniature copy of the core and heat exchangers, the methodology of "black boxes", simplified objects that simulate the integral characteristics of real equipment, is used. The fluid motion in these is assumed to be unidirectional (parallel to the force of gravity) in conditions of equal resistance to acceleration 
(or equal deceleration), $f^{\text {core }}, f^{\mathrm{DHX}}, f^{\mathrm{fHX}}$ (i.e. in the core, in the emergency heat removal system (EHRS) heat exchanger (DHX), and in the intermediate heat exchanger (IHX)), and uniform volumetric heat release, $H^{\text {core }}, H^{\mathrm{DHX}}, H^{\mathrm{iHX}}\left(Q_{v}^{\text {core }}\right.$, $Q_{v}^{\mathrm{DHX}}, Q_{v}{ }^{\mathrm{IHX}}$ hereinafter). A facility with such characteristics was used in experiments by Japanese researchers; see Fig. 2 for its design (Eguchi and Takeda 1993).

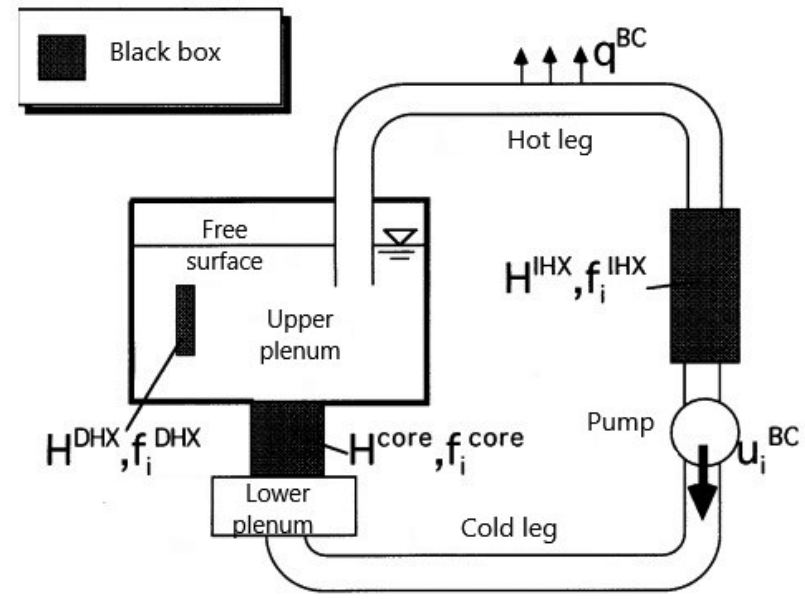

Figure 2. A model of the reactor facility's primary circuit loop using "black boxes".

With respect to "black boxes", therefore, it is only the specified input parameters and the resultant output data that is known, being compared with the required values. The details of the processes in the objects as such are not taken into account or are not available for observation as the whole. The proposed method provides for the accuracy of the parameter estimation that is acceptable in practical terms and is comparable to the accuracy of calculations based on the verification codes (Ishii and Kataoka 1982, Ishii and Kataoka 1984, Eguchi and Takeda 1993, Ieda et al. 1993, Takeda and Koga 1993, Eguchi et al. 1997).

The paper considers simulation of the developed natural convection process in a liquid-metal coolant in the upper plenum of a reactor using a water test facility. From the standpoint of hydrodynamics, liquid sodium and water behave in a very similar way, so hydrodynamic simulation of a flow of one fluid with the use of another does not cause complications. However, a difficulty arises in simulation of thermal processes because of the Prandtl criterion for liquid sodium being three orders of magnitude as small as for water. When considering natural circulation in the near-wall layer, the Nusselt number is found to depend on the product of $\mathrm{Gr} \times \mathrm{Pr}$ for water and on the product of $\mathrm{Gr} \times \mathrm{Pr}^{2}$ for liquid metals. The convective heat transfer in channels is also expressed by different criterion dependences for water and liquid metal environments. Therefore, experimental simulation of the natural convection processes in the upper plenum of a fast reactor requires the wall heat transfer conditions not to be considered, these to be possibly replaced by code-based calculations, while simplifying at the same time the initial differential equations.
Based on the conditions defined, a system of similarity criteria can be obtained as represented by the following expressions:

- $\mathrm{Eu}=\Delta p /\left(\rho U^{2}\right)-$ Euler criterion;

- $\mathrm{Ri}=g \beta \Delta T L / U^{2}-$ Richardson criterion;

- $\operatorname{Re}=U L / v-$ Reynolds criterion;

- $\mathrm{Pe}=U L / a-$ Peclet criterion;

- Ho $=\tau^{*}=\tau U / L-$ homochronicity criterion;

- $N=Q /\left(\rho C U L^{2} \Delta T\right)-$ dimensionless group reflecting the heat balance.

Here, $\Delta p$ is the pressure drop, $\mathrm{Pa} ; \rho$ is the fluid density, $\mathrm{kg} / \mathrm{m}^{3} ; U$ is the characteristic fluid flow velocity, $\mathrm{m} / \mathrm{s} ; g$ is the acceleration of gravity, $\mathrm{m} / \mathrm{s}^{2} ; \beta$ is the coefficient of thermal expansion, $1 / \mathrm{K} ; \Delta T$ is the characteristic temperature difference, $\mathrm{K} ; L$ is the characteristic dimension, $\mathrm{m} ; \mathrm{v}$ is the kinematic viscosity, $\mathrm{m}^{2} / \mathrm{s} ; a$ is the thermal diffusivity, $\mathrm{m}^{2} / \mathrm{s} ; \tau$ is the characteristic time, $\mathrm{s} ; Q$ is the thermal power, $\mathrm{W}$; and $C$ is the specific heat capacity, $\mathrm{J} /(\mathrm{kg} \times \mathrm{K})$.

In the mode of transition from forced circulation to natural circulation, as well as in the mode of steady-state natural circulation, the Richardson and Euler criteria are of a paramount importance. In this case, the effect of the Reynolds and Peclet numbers is not critical (Ushakov and Sorokin 1998).

The investigation results show that simulation of natural convection in a reactor using water shall reasonably use models with small dimensions to increase the power density in the model and the temperature drop to acceptable values. With a decay power density in the BN-1200 reactor equal to $75 \mathrm{MW}$, the power density in an experimental 1:10 model at extremely low velocity and temperature drop values is about $400 \mathrm{~W}$. Therefore, one needs to increase the power density in the model by nearly three orders of magnitude, while the values of the velocity in the model increase by an order of magnitude, and the temperature drop values increase by two orders of magnitude.

\section{Obtaining scale system}

To obtain equations to describe convective heat transfer during natural convection, we shall respectively write the liquid variable temperature and variable density as:

$$
\begin{aligned}
& T=T_{0}+T^{\prime}, \\
& \rho=\rho_{0}+\rho^{\prime},
\end{aligned}
$$

where $T_{0}$ and $\rho_{0}$ are some constant mean temperature and density values, (deviations from which are measured) from which the unevenness of values is measured; and $T^{\prime}$ and $\rho$ 'are the variations of the temperature and density values. Due to a small temperature variation, $T^{\prime}$, the density variation it leads to, $\rho^{\prime}$, is also small:

$$
\rho^{\prime}=(\partial \rho / \partial T) T^{\prime}=-\rho_{0} \beta T^{\prime} .
$$


And in the expression for pressure

$$
p=p_{0}+p^{\prime}
$$

the $p_{0}$ value (the value from which the variation in the $p^{\prime}$ quantity is measured) will not be constant. It is defined by the pressure corresponding to the mechanical equilibrium at a constant temperature and a constant density $\left(T_{0}\right.$ and $\left.\rho_{0}\right)$. This pressure value is variable with height according to the hydrostatic equation

$$
p_{0}=\rho_{0} g z+\text { const }
$$

for which the $z$ coordinate is measured vertically upward.

We shall introduce the rearrangement of the Navier-Stokes equation, which looks as follows in the field of gravity (Polezhayev 1967, Isachenko et al. 1975, Isayev et al. 1979, Kirillov and Bogoslovskaya 2000, Mikhatulin and Chirkov 2009):

$$
\partial v / \partial t+(v \nabla) v=-\nabla p / \rho+v \Delta v+g
$$

Here, $t$ is the time; $v$ is the vector velocity field; $\nabla$ is the Hamilton vector differential operator; $\Delta$ is the Laplace vector operator; and $v$ is the coefficient of kinematic viscosity. By substituting the expressions for the pressure and density variables, we get

$$
\frac{\nabla p}{\rho}=\frac{\nabla p_{0}}{\rho_{0}}+\frac{\nabla p^{\prime}}{\rho_{0}}-\frac{\nabla p_{0}}{\rho_{0}^{2}} \rho^{\prime} .
$$

Substituting (3) and (5) to (7), we get

$$
\frac{\nabla p}{\rho}=g+\frac{\nabla p^{\prime}}{\rho_{0}}+g \beta T^{\prime}
$$

Having substituted this expression in the Navier-Stokes equation and introducing the Kronecker coefficient, $\delta_{i j}$, we finally get

$$
\frac{\partial v}{\partial t}+(v \nabla) v=-\frac{\nabla p^{\prime}}{\rho}+v \Delta v-g \beta T^{\prime} \delta_{i j},
$$

where $\delta_{i j}=1$ for $i=j$ and $\delta_{i j}=0$ in the other cases.

We shall write the equation of heat transport in an incompressible liquid while omitting the component that contains viscosity since it is small in conditions of free convection as compared with other terms in the equation:

$$
\frac{\partial T^{\prime}}{\partial t}+v \nabla T^{\prime}=a \Delta T^{\prime}
$$

Together with the flow continuity equation

$$
\operatorname{div} v=0
$$

expressions (9) and (10) complete the system of equations describing free convection. However, it is necessary to make some corrections taking into account the introduction of the "black box" concept into the system. We shall additionally introduce $f$ as resistance to acceleration acting inside the "black box", $\mathrm{m} / \mathrm{s}^{2} ; Q /(\rho C)$ as the mod- ified form of volumetric heat release inside the "black box"; and $S(\Omega)$ as a coefficient equal to unity inside the "black box" and to zero outside it. In this case, $Q$ is the volumetric heat release, $\mathrm{W} / \mathrm{m}^{3}$. With regard for these values, the system of convection equations will finally take the following form

$$
\begin{gathered}
\operatorname{div} v=0 \\
\frac{\partial v}{\partial t}+(v \nabla) v=-\frac{\nabla p^{\prime}}{\rho}+v \Delta v-g \beta T^{\prime} \delta_{i j}+f_{i} S(\Omega) \\
\frac{\partial T^{\prime}}{\partial t}+v \nabla T^{\prime}=a \Delta T^{\prime}+\frac{Q S(\Omega)}{\rho C}
\end{gathered}
$$

It is necessary to add the following boundary conditions to the above system: $v_{i}=0$ as the wall boundary velocity; $p=p_{0}$ as the pressure on the free surface boundary; and $q_{i}$ $=q_{i}^{\mathrm{BC}}$ as the heat flux density at the liquid boundary (i.e. with the boundary condition), W/m² (Eguchi et al. 1997).

To obtain the scales of quantities, the velocity, pressure, temperature, coordinates, time and heat flux density need to be presented in a dimensionless form (indexed “*”). In this form, the quantities are expressed through the characteristic velocities, $U$, the temperature difference, $\Delta T$, and the size, $L$ :

$$
\begin{gathered}
U_{i}^{*}=v_{i} / U ; p^{*}=p^{\prime} /\left(\rho U^{2}\right) ; T^{*}=T^{\prime} / \Delta T ; x_{i}^{*}=x_{i} / L \\
t^{*}=t U / L ; q_{i}^{*}=q_{i} L /(a \Delta T \rho C) .
\end{gathered}
$$

Substituting these quantities in system (12), we get

$$
\frac{\partial U_{i}^{*}}{\partial t^{*}}=0
$$

$\frac{\partial U_{i}^{*}}{\partial t^{*}}+U_{j}^{*} \frac{\partial U_{i}^{*}}{\partial x_{j}^{*}}=\left(\frac{v}{U L}\right) \frac{\partial^{2} U_{i}^{*}}{\partial x_{j}^{* 2}}-\left(\frac{\beta \Delta T g L}{U^{2}}\right) T^{*} \delta_{i j}-\frac{\partial p^{*}}{\partial x_{i}^{*}}+\left(\frac{f L}{U^{2}}\right) S(\Omega)$

$$
\frac{\partial T^{*}}{\partial t^{*}}+U_{j}^{*} \frac{\partial T^{*}}{\partial x_{j}^{*}}=\left(\frac{a}{U L}\right) \frac{\partial^{2} T^{*}}{\partial x_{j}^{* 2}}+\left(\frac{Q L}{\rho C U \Delta T}\right) S(\Omega) .
$$

The groups in parentheses in system (14) are dimensionless quantities, the scales the equality of which is to be gained to achieve the model and full-size object identity. We shall write these as:

$$
\begin{gathered}
N_{1}=v / U L ; N_{2}=g \beta \Delta T L / U^{2} ; \\
N_{3}=f L / U^{2} ; N_{4}=a / U L ; N_{5}=Q L /(\rho C U \Delta T) .
\end{gathered}
$$

It can be noted that some of these groups meet the wellknown similarity criteria (Kirpichev 1953, Gukhman 1973, Kirillov et al. 1990):

$$
\begin{gathered}
N_{1}=v / U L=1 / \mathrm{Re} ; \\
N_{2}=g \beta \Delta T L / U^{2}=\mathrm{Ri} ; \\
N_{4}=a / U L=1 / \mathrm{Pe} .
\end{gathered}
$$


The $N_{3}$ criterion can be reconstructed to a simpler form using pressure drop $\Delta p$. The total resistance force acting against the fluid motion in the "black box" can be expressed as

$$
k_{1} \rho L^{3} f=k_{2} L^{2} \times \Delta p
$$

where the products of $k_{1} \rho L^{3}$ and $k_{2} L^{2}$ are the mass and the cross-section, respectively. Expression (16) can be written as $f=k_{3} \times \Delta p / \rho L$, where $k_{3}=k_{2} / k_{1}$, and variables $k_{1}, k_{2}$, $k_{3}$ are the proportional constants due to their geometric similarity, so then

$$
N_{3}=k_{3} \times \Delta p / \rho U^{2} .
$$

The $N_{5}$ criterion can also be modified in a similar way by introducing quantity $Q_{0}$, the total amount of heat transferred per second in the "black box". We shall associate it with the volumetric heat release using the proportionality coefficient, $k 1$, (Eguchi and Takeda 1993):

$$
Q_{0}=k_{1} L^{3} Q
$$

Now, in the modified form for natural circulation, the list of similarity criteria looks as follows:

$$
\begin{gathered}
N_{1}=v / U L=1 / \mathrm{Re} ; \\
N_{2}=g \beta \Delta T L / U^{2}=\mathrm{Ri} ; \\
N_{3}=\Delta p / \rho U^{2} ; \\
N_{4}=a / U L=1 / \mathrm{Pe} ; \\
N_{5}=Q_{0} /\left(\rho C U \Delta T L^{2}\right) .
\end{gathered}
$$

\section{Deriving quantity ratios between the model and the object}

Expressions for criteria $N_{2}$ and $N_{5}$ satisfy the equality of these quantities for the model and the full-size object (Eguchi and Takeda 1993):

$$
\begin{gathered}
\left(g \beta \Delta T L / U^{2}\right)_{m}=\left(g \beta \Delta T L / U^{2}\right)_{r}, \\
{\left[Q_{0} /\left(\rho C U \Delta T L^{2}\right)\right]_{\mathrm{m}}=\left[Q_{0} /\left(\rho C U \Delta T L^{2}\right)\right]_{\mathrm{r}},}
\end{gathered}
$$

where subscripts $m$ and $r$ designate the model and the reactor facility, respectively.

We can obtain hence the ratios of the characteristic quantities. From the expression (19) we shall get

$$
\begin{gathered}
U_{m}^{2} / U_{r}^{2}=(g \beta \Delta T L)_{m} /(g \beta \Delta T L)_{r}= \\
{\left[(g \beta L)_{m} /(g \beta L)_{r}\right] \times\left[\Delta T_{m} / \Delta T_{r}\right] .}
\end{gathered}
$$

From equation (20) we shall express

$$
\Delta T_{m} / \Delta T_{r}=\left[Q_{0} /\left(\rho C U L^{2}\right)\right]_{m} /\left[Q_{0} /\left(\rho C U L^{2}\right)\right]_{r} .
$$

Substituting (22) in (21), we shall get

$$
U_{m}^{2} / U_{r}^{2}=\left[\left(Q_{0} g \beta\right) /(\rho C U L)\right]_{m} \times\left[(\rho C U L) /\left(Q_{0} g \beta\right)\right]_{r}
$$

or by transposing the velocity to the left-hand side and eliminating the degree,

$$
\begin{gathered}
U_{m} / U_{r}=\left(Q_{m} / Q_{r}\right)^{1 / 3} \times\left[(\beta g)_{m} /\right. \\
\left.(\beta g)_{r}\right]^{1 / 3} \times\left[(\rho C)_{r} /(\rho C)_{m}\right]^{1 / 3} \times\left(L_{r} / L_{m}\right)^{1 / 3} .
\end{gathered}
$$

Using this correlation, we shall get a new expression for the temperature ratio substituting it in (22):

$$
\begin{gathered}
\Delta T_{m} / \Delta T_{r}=\left(Q_{m} / Q_{r}\right)^{2 / 3} \times\left[(\beta g)_{r} /(\beta g)_{m}\right]^{1 / 3} \\
\times\left[(\rho C)_{r} /(\rho C)_{m}\right]^{2 / 3} \times\left(L_{r} / L_{m}\right)^{5 / 3} .
\end{gathered}
$$

We shall derive the correlations for the pressure drops and the characteristic time:

$$
\begin{gathered}
\Delta p_{m} / \Delta p_{r}=\rho_{m} / \rho_{r} \times\left(Q_{m} / Q_{r}\right)^{2 / 3} \times\left[(\beta g)_{m} /\right. \\
\left.(\beta g)_{r}\right]^{2 / 3} \times\left[(\rho C)_{r} /(\rho C)_{m}\right]^{2 / 3} \times\left(L_{r} / L_{m}\right)^{2 / 3}, \\
\tau_{m} / \tau_{r}=\left(Q_{r} / Q_{m}\right)^{1 / 3} \times\left[(\beta g)_{r} /(\beta g)_{m}\right]^{1 / 3} \times \\
{\left[(\rho C)_{m} /(\rho C)_{r}\right]^{1 / 3} \times\left(L_{m} / L_{r}\right)^{4 / 3} .}
\end{gathered}
$$

We shall also write the ratios for the Reynolds and Peclet criteria:

$$
\begin{gathered}
\operatorname{Re}_{m} / \operatorname{Re}_{r}=v_{r} / v_{m} \times\left(Q_{m} / Q_{r}\right)^{1 / 3} \times\left[(\beta g)_{m} /\right. \\
\left.(\beta g)_{r}\right]^{1 / 3} \times\left[(\rho C)_{r} /(\rho C)_{m}\right]^{1 / 3} \times\left(L_{m} / L L_{r}\right)^{2 / 3}, \\
\mathrm{Pe}_{m} / \mathrm{Pe}_{r}=a_{r} / a_{m} \times\left(Q_{m} / Q_{r}\right)^{1 / 3} \times\left[(\beta g)_{m} /(\beta g)_{r}\right]^{1 / 3} \\
\times\left[(\rho C)_{r} /(\rho C)_{m}\right]^{1 / 3} \times\left(L_{m} / L_{r}\right)^{2 / 3} .
\end{gathered}
$$

Thus, correlations have been obtained which allow estimating the factors for scaling quantities between the model and the reactor facility. These expressions depend only on the thermophysical parameters of the fluids, the geometric scale, and the power ratio for the model and the reactor facility.

\section{Estimation of factors for scaling of model-to-object values}

As shown in (Ishii and Kataoka 1982, Ishii and Kataoka 1984, Eguchi and Takeda 1993, Ieda et al. 1993, Takeda and Koga 1993, Eguchi et al. 1997), an increase in the coolant temperature is recorded at a certain time point during the experiments in the course of changing from forced circulation to natural circulation. In this respect, not only the magnitude of the temperature growth to the peak value in the transition process is important, but the 
time of this peak occurrence as well. For this reason, apart from the velocity, pressure, and temperature scaling factors, the time scaling factor is also considered. The BN1200 reactor design is considered as the simulated object. Since the performance of BN-1200 has not yet been finally determined, it is possible to update the scaling factors as soon as the reactor design performance is specified. In this case, if the V-200 test facility with the characteristics in the natural circulation mode is taken as the reactor facility model, the estimated scaling factors are obtained using the parameters given in Table 1.

Table 1. Model and reactor facility parameters used to obtain scaling factors

\begin{tabular}{lcc}
\hline \multicolumn{1}{c}{ Parameter } & For model & For reactor facility \\
\hline Coolant density, $\mathrm{kg} / \mathrm{m}^{3}$ & 971 & 800 \\
Flow rate, $G, \mathrm{~m}^{3} / \mathrm{h}$ & 6.6 & 7356 \\
Scale factor, $L_{r} / L_{m}$ & \multicolumn{2}{c}{$22.3(10)^{*}$} \\
Kinetic viscosity, $\mu, \mathrm{m}^{2} / \mathrm{s}$ & $0.55 \cdot 10^{-6}$ & $0.28 \cdot 10^{-6}$ \\
Volumetric expansion coefficient, $\beta, 1 / \mathrm{K}$ & $0.53 \cdot 10^{-3}$ & $0.62 \cdot 10^{-3}$ \\
Thermal power, $\mathrm{Q}, \mathrm{MW}$ & 0.00833 & 75 \\
Specific heat capacity, $C p, \mathrm{~kJ} /(\mathrm{kg} \times \mathrm{K})$ & 4.1 & 1.2 \\
\hline
\end{tabular}

* The vessel diameter taken as the defining dimension.

Using the presented parameters and the given expressions for the scaling factors for quantities (24) through (27), we shall obtain the following values for various geometric scales (Table 2).

\section{References}

- Ashirmetov MR, Yershov GA (2021) General design features of a BN1200 unit. http://www.proatom.ru/modules.php?name=News\&file=article\&sid=4279.25.01.2013 [accessed Jun. 20, 2021] [in Russian]

- Bomelburg HJ (1968) An Evaluation of the Applicability of Water Model Testing to Liquid Metal Engineering Problems. General, Miscellaneous and Progress Reports, LMEC-68-4. Liquid Metal Engineering Center, Atomics International. Feb. 26. https://doi. org/10.2172/4552193

- Eguchi Y, Takeda H (1993) Experimental and Computational Study of Prediction of Natural Circulation in Top-entry Loop-type FBR Specialists' Meeting of IAEA: Evaluation of Decay Heat Removal by Natural Convection. O-arai Engineering Center, PNC, Japan. Feb. 22-25.

- Eguchi Y, Takeda H, Koga T, Tanaka N, Yamamoto K (1997) Quantitative prediction of natural circulation in an LMFR with a similarity law and a water test. Nuclear Engineering and Design 178(3): 295-307. https://doi.org/10.1016/S0029-5493(97)00234-3

- Gukhman AA (1973) Introduction to the Similarity Theory. Textbook. $2^{\text {nd }}$ edn. Vysshaya Shkola Publ., Moscow, 296 pp. [in Russian]

- Ieda Y, Kamide H, Ohshima H, Sugawara S, Ninokata H (1993) Strategy of Experimental Studies in PNC on Natural Convection Decay Heat Removal. Specialists' Meeting of IAEA: Evaluation of Decay Heat Removal by Natural Convection. O-arai Engineering Center, PNC, Japan. Feb. 22-25.

\section{Conclusions}

The results of code-based numerical simulations for the

Table 2. Scaling factors for quantities depending on geometric scale

\begin{tabular}{|c|c|c|c|}
\hline$L_{r} / L_{m}$ & $U_{r} / U_{m}$ & $\Delta T_{r} / \Delta T_{m}$ & $\tau_{r} / \tau_{m}$ \\
\hline 22.3 & 17.86 & 5.67 & 0.07 \\
\hline 10 & 23.34 & 21.59 & 0.21 \\
\hline
\end{tabular}

thermohydraulic processes taking place in a reactor facility could be taken as an indirect proof for the reliability of the obtained scaling factors.

It can be preliminarily concluded that the processes involved in natural circulation of sodium coolant in the fast reactor tank can be simulated with an adequate accuracy using water test facilities. It should be however noted that it is impossible to simulate the processes of forced and natural circulation using the same test facility, since they require different similarity criteria to be met (Suh et al. 1989).

A further study requires updating the range of characteristics for the core and the $\mathrm{BN}-1200$ reactor facility as the whole to determine more accurately the characteristics for designing or upgrading water test facilities which can be used to simulate the processes of natural circulation in the fast reactor tank.

- Isachenko VP, Osipova VA, Sukomel AS (1975) Heat Transfer. Energiya Publ., Moscow, 416 pp. [in Russian]

- Isayev SI, Kozhinov IA, Kofanov VI, Leontyev AI, Mironov BM, Nikitin VM, Petrazhitsky GB, Khvostov VI, Chukayev AG, Shishov EV, Shkola VV (1979) The Heat and Mass Transfer Theory. Vysshaya Shkola Publ., Moscow, 495 pp. [in Russian]

- Ishii M, Kataoka I (1982) Scaling Criteria for LWR's under Single-Phase and Two-Phase Natural Circulation. Joint NRC/ANS Meeting on Basic Thermal Hydraulic Mechanisms in LWR Analysis. Bethesda, MD, USA. Sept. 14-15. https://doi.org/10.2172/6312011

- Ishii M, Kataoka I (1984) Scaling laws for thermal-hydraulic system under single-phase and two-phase natural circulation. Nuclear Engineering and Design 81(3): 411-425. https://doi.org/10.1016/00295493(84)90287-5

- Kirillov PL, Bogoslovskaya GP (2000) Heat and Mass Transfer in Nuclear Power Systems. Energoatomizdat Publ., Moscow, 458 pp. [in Russian]

- Kirillov PL, Yuryev YuS, Bobkov VP (1990) Handbook of Thermohydraulic Calculations (Nuclear Reactors, Heat Exchangers, Steam Generators). $2^{\text {nd }}$ edn. Energoatomizdat Publ., Moscow, 360 pp. [in Russian]

- Kirpichev MV (1953) The Similarity Theory. AN SSSR Publ., Moscow, 96 pp. [in Russian]

- Mikhatulin DS, Chirkov AYu (2009) The Compendium of Lectures in Heat and Mass Transfer. MGTU Publ., Moscow, 148 pp. [in Russian] 
- Mitenkov FM (2021) The opportunities for developing fast neutron breeder reactors. http://elib.biblioatom.ru/text/mitenkov_razmyshleniya-o-perezhitom_2004/go,170/ [accessed Jun. 20, 2021] [in Russian]

- Polezhayev VI (1967) Numerical Calculation of the Navier-Stokes Equations for the Flowing and Heat Transfer in a Closed Two-dimensional Region. Cand. Sci. (Engineering) Diss. MEI Publ., Moscow, 196 pp. [in Russian]

- Suh KY, Todres NE, Rohsenow WM (1989) Mixed convective low flow pressure drop in vertical rod assemblies: II Experimental Validation. Transactions of the ASME 111(4): 966-973. https://doi. org/10.1115/1.3250812

- Takeda H, Koga T (1993) Study on Similarity Rule for Natural Circulation Water Test of LMFBR. Specialists' Meeting of IAEA:
Evaluation of Decay Heat Removal by Natural Convection. O-arai Engineering Center, PNC, Japan. Feb. 22-25.

- Ushakov PA, Sorokin AP (1993) Concerning the Possibilities for Modeling the Fuel and the Coolant Temperature Distributions in Liquid-Metal Cooled Reactors using Water and Air. IPPE Preprint-2346, Obninsk, FEI Publ., 34 pp. [in Russian]

- Ushakov PA, Sorokin AP (1998) Role of the Reynolds number in modeling natural convection in liquid metals. Atomic Energy 84(5): 309-313. https://doi.org/10.1007/BF02414877

- Ushakov PA, Sorokin AP (1999) Modeling Problems of Emergency Natural Convection Heat Removal in the Upper Plenum of Fast Reactors Using Water. Proc. of the $9^{\text {th }}$ Intern. Topical Meeting on Nuclear Reactor Thermal Hydraulics (NURETH-9). USA, October 3-8. 